\title{
Artes performativas como presença compartilhada: a potência de afeto na imprevisibilidade do encontro entre corpos*
}

\author{
Milene Lopes Duenha*
}

Recibido: noviembre 15 de 2019 • Aceptado: 17 de febrero de 2020

\section{Resumo}

Este artigo aborda a presença do artista como relação, problematizando a ideia de previsibilidade da recepção na experiência artística presencial. Pesquisas sobre o corpo e seus modos de percepção se apoiam na noção de embodiment (mente incorporada), e de corpo poroso, diante de estudos advindos da arte, da filosofia e das neurociências que permitem um percurso cartográfico acerca do tema. Noções de partilha e afeto são apresentadas com referência em escritos de Jacques Rancière e Benedictus de Spinoza respectivamente. O relato de uma das experiências do coletivo brasileiro 'Mapas e Hipertextos' exemplifica, na prática, via metodologia hipotético-dedutiva, a ideia de imprevisibilidade dos efeitos no encontro entre os corpos, e a possibilidade de uma produção

"Este artigo de resultado de investigação e reflexão foi desenvolvido durante a pesquisa de doutorado em Teatro no Programa de Pós-Graduação em Teatro na Universidade do Estado de Santa Catarina, Florianópolis, Brasil com financiamento pela Coordenação de Aperfeiçoamento de Pessoal de Nível Superior (CAPEs) entre os anos de 2014 e 2018. A pesquisa também foi contemplada pelo Programa de Doutorado Sanduíche no Exterior pela Coordenação de Aperfeiçoamento de Pessoal de Nível Superior na Universidade de Lisboa, Portugal em 2017.

Citar como: Duenha, M. L. (2019). Artes performativas como presença compartilhada: a potência de afeto na imprevisibilidade do encontro entre corpos. Revista de Investigación Cuerpo, Cultura y Movimiento, 10(1), 89-109. DoI: https://doi.org/10.15332/2422474x/5963

* Doutora em Teatro pelo Programa de Pós-Graduação em Teatro na Universidade do Estado de Santa Catarina, Brasil. Dançarina, atriz e performer, atuante nos coletivos Mapas e Hipertextos e projeto Corpo, Tempo e Movimento. É Professora Colaboradora no Curso de Licenciatura e Bacharelado em Dança da Universidade Estadual do Paraná, Curitiba, Brasil. E-mail: miduenha@yahoo.com.br. oRcID: http://orcid.org/0000-0002-2316-0408 
artística cuja potência de afeto emerge entre os corpos presentes que compõem no ambiente.

Palavras-chave: presença cênica, práticas performativas, espectador, expectativa, corpo em relação 


\section{Las artes escénicas como presencia compartida: el poder del afecto en la imprevisibilidad del encuentro entre cuerpos}

Este artículo aborda la presencia del artista como relación, a partir de la problematización de la idea de previsibilidad de la recepción en la experiencia artística. Las investigaciones sobre el cuerpo y sus modos de percepción se apoyan en el concepto de embodiment ('encarnación' o 'mente encarnada') y de cuerpo poroso, frente a estudios provenientes del arte, la filosofía y las neurociencias que permiten un recorrido cartográfico del tema. Los conceptos de compartir y afecto se encuentran como referencias a los escritos de Jacques Rancière y Benedictus de Spinoza, respectivamente. El relato de una de las experiencias del colectivo brasileño Mapas e Hipertextos ejemplifica, en la práctica, a través del método hipotético-deductivo, la idea de imprevisibilidad de los efectos en el encuentro entre los cuerpos, y la posibilidad de una producción artística cuyo poder de afecto emerge entre los cuerpos presentes en el ambiente.

Palabras clave: presencia escénica, prácticas performativas, espectador, expectativa, cuerpo en relación. 


\section{Performing arts as shared presence: the power of affection in the unpredictability of the encounter between bodies}

Abstract

This article analyzes the artist's presence as relation, based on the problematization of the idea of predictability of the reception in the artistic experience. The research on the body and its modes of perception are based on the concept of embodiment, and the porous body, with regards to studies derived from art, philosophy and neuroscience that allow a cartographic journey on the topic. The concepts of sharing and affection are found as references to the writings of Jacques Rancière and Benedictus de Spinoza, respectively. An experience of 'Mapas e Hipertextos', a Brazilian Group, is an example, in practice, through the hypothetical-deductive methodology, of the idea of unpredictability of the effects in the encounter between bodies, and the possibility of an artistic production whose power of affection arises between the bodies present in the environment.

Keywords: scenic presence, performing practices, spectator, expectation, body in relation. 


\section{Introdução e metodologia: presença como relação}

Muitas são as abordagens acerca da noção de presença nas artes performativas. Alguns estudos a trazem como potencial de encantamento do público, outros como moção de energia e dilatação do corpo do artista e outros como qualidade performativa que se faz em consideração ao entorno. Tais abordagens oferecem uma perspectiva que mantém a figura do artista com certa centralidade, responsável por prender a atenção do público por meio de suas técnicas e modos de fazer. A discussão aqui evocada questiona a ideia de centralidade da figura do artista ao considerar os afetos que incorrem no encontro entre corpos e sugere a consideração de uma noção de presença compartilhada nesse fazer.

A noção de afeto trazida para essa discussão tem referência na teoria desenvolvida pelo filósofo holandês Benedictus de Spinoza (2009 [1677]). O convite à ampliação da percepção desse termo filosófico para as práticas performativas é lançado como possibilidade de atualização de uma concepção de presença cênica que imprime certa distância ente artista performer e espectador. A compreensão do termo compartilhar - partilhar com - denota níveis de envolvimento de ambos os partícipes da relação e se desenha nesse artigo a partir da discussão levantada pelo filósofo francês Jacques Rancière (2005) sobre partilha do sensível.

Esse trabalho de caráter qualitativo traz uma abordagem hipotético-dedutiva que se faz via processo cartográfico de revisão bibliográfica e exposição de investigação criativa. Tal proposição se desenha em um trajeto de pesquisa teórico-prática em arte que perpassa acepções de corpo e seus modos de percepção, de partilha e afeto, e que tem ressonância nos trabalhos

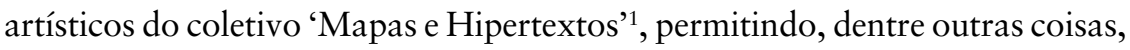

1 O coletivo 'Mapas e Hipertextos', existente desde 2012 nas cidades de Florianópolis, Santa Catarina e Curitiba, Paraná, Brasil, trata-se da reunião de um grupo de artistas pesquisadoras e pesquisadores da Universidade do Estado de Santa Catarina com o intuito de realizar práticas investigativas em artes presenciais por meio de ações de mapeamento físico e virtual das relações em sociedade. Esse grupo se destina também à experimentação de questões levantadas nas pesquisas acadêmicas e artísticas de cada integrante abordando conceitos como: presença/ausência, fracasso/ sucesso, ética, composição em dança e performance, relação entre espaço virtual e estrutura social, site specifc, política no corpo e percepção inventiva, dentre outros. No ano de 2014, momento em que ocorreu a referida investigação, o coletivo era composto por Cecília Lauritzen, Diana Gilardenghi, Diana Piazza, Mayara Marengo, Michele Louise Schiocchet, Milene Lopes Duenha, Paloma Bianchi e Raquel Purper. Outras informações sobre o coletivo podem ser encontradas em: https:// mapasehipertextos.wordpress.com/ 
a constatação de que não é possível prever os afetos nos encontros ou os efeitos de nossa presença em relação aos outros corpos na proposição artística.

A exposição de um dos processos compositivos do coletivo 'Mapas e Hipertextos', e sua posta em relação, é trazida por meio de relato de experiência que acontece em primeira pessoa, uma vez que também integro esse coletivo de pesquisa e criação em artes presenciais. O relato, além de trazer as questões levantadas inicialmente nesse texto, oferece parâmetros de discussão acerca de processos de construção cênica que se voltam a ideia de participação do público. Por se tratar de uma pesquisa em arte, as fronteiras entre prática e teoria, metodologia de escrita acadêmica e metodologia de investigação criativa se borram em favor de uma aproximação mais estreita entre os campos da criação em arte e da pesquisa científica.

\section{Breve cartografia acerca do tema}

No livro 'Embodiment and presence: the ontology of presence reconsidered' a professora de Filosofia e Ciências Humanas Suzanne Jaeger (2006) aponta para a presença do artista como uma configuração e reconfiguração de uma força em resposta ao ambiente, o que exige um completo engajamento do corpo no aqui-agora, considerando a singularidade do momento presente. Diante desse engajamento, o espectador seria capaz de perceber esse desencadeamento de afetações, o que conferiria a ele aquilo que se conhece por presença de palco.

O encenador italiano Eugenio Barba tem vasta pesquisa prática direcionada à questão da presença cênica a partir da segunda metade do século xx. Sua perspectiva desse tema aponta para a ampliação do potencial expressivo do corpo, o que permitiria que o artista envolvesse o espectador em suas ações. No livro 'A arte secreta do ator: dicionário de antropologia teatral' (1995) uma parte desse estudo é dedicada a princípios capazes de conferir presença ao artista, dentre esses princípios se encontra a ideia de dilatação do corpo, que pode, segundo o autor, ser visível até na aparente imobilidade, devido à moção de energias que se evidencia nessa prática.

Por sua vez, a pesquisadora alemã Erika Fischer-Lichte, no livro 'Estética de lo performativo' (2011) discute uma noção de presença como qualidade performativa, e não expressiva, que ocorre por meio de processos específicos de corporalização, engendrados no corpo fenomênico do artista, 
o que o conduziria à dominação do espaço e conquista da atenção daqueles que assistem.

Tais discussões têm relevo no fazer das artes performativas ao desenvolver conceitos e procedimentos capazes de colocar essa prática como processo de pesquisa constante. Diante dessa mobilidade, alguns questionamentos tornam-se pertinentes aos processos de feitura e posta em relação das obras como: a abordagem do público e os modos de se estabelecer relação entre audiência e artista; e a centralidade da figura do artista na relação presencial. Se considerarmos que a recepção do público não é passível de previsão e controle, a ideia de dilatação do corpo, de encantamento, aparece muito mais como convite ao engajamento do espectador na ação, do que meio de garantir a potência da experiência presencial. A potência da obra não depende somente do artista propositor ou daquilo que é apresentado, mas também do que ocorre entre os corpos como trânsito de afetos no momento desse encontro na arte.

A noção de afeto é abordada na filosofia de Spinoza (2009 [1677]) como fator capaz de aumentar ou diminuir nossa potência de agir. Em seu livro 'Ética' Spinoza (2009 [1677]) traz a afirmação de que os efeitos dos encontros não são previsíveis, porque os afetos ocorrem independentemente de nossa vontade. Porém, ao identificar as afecções, perceber como os afetos marcam o corpo, nós poderíamos, segundo o filósofo, refrear as paixões tristes, que diminuem nossa potência de agir. A acepção espinosiana de afeto é trazida para essa discussão do universo das artes presenciais como possibilidade de se elasticizar esse conceito e utilizarmos uma percepção das afecções como parâmetro de operação na arte, como levantamento de dados a serem considerados durante o desenvolvimento prévio de ações a serem levadas ao público e também como termômetro das relações estabelecidas no aqui-agora diante da realização dessas ações (Duenha, 2014).

Ao considerarmos tais conexões nos processos compositivos em artes presenciais, torna-se perceptível que não se trata somente de um treinamento para se conquistar uma qualidade diferenciada de presença, mas talvez, de uma prática que convide à reflexão sobre questões como: Que presenças poderíamos ser diante de uma configuração relacional de trânsito de afetos? Que recursos emergem diante da possibilidade de sermos surpreendidas e surpreendidos pela recepção do público? E ainda, como permitir que o que articulamos previamente em nosso trabalho seja contaminado pelas emergências dessa configuração de relações que se desenha no aqui-agora? 
Algumas teorias e práticas artísticas nos oferecem bases para uma circunscrição da noção de presença em relação, essa que considera o espectador como participante ativo, assim como afirma Jacques Rancière (2010), e a artista/o artista-performer como quem convida à experiência baseando-se em suas percepções e afetos emergentes no aqui-agora do encontro entre as presenças do ambiente. Assim, alguns elementos são aqui apresentados como possibilidade de se transferir a potência do acontecimento presencial para o espaço "entre" os corpos presentes, e não no que se configura previamente como "obra de arte" detentora de uma aura que marca a distância entre aquele que a propõe e aquela/aquele que a contempla.

Quando no teatro há o rompimento de uma suposta quarta parede (que mantinha o público como uma espécie de espectador televisivo, que apenas assistia passivamente aquilo que ocorria no palco do teatro, sem possibilidade de interferência nas ações ali apresentadas) e se passa a direcionar as falas, o olhar, as ações físicas em geral, para o público, tornando-o cúmplice daquilo que vê, outro entendimento do fazer artístico presencial se inaugura. O encenador alemão Bertolt Brecht é um dos atuantes, no início do século $\mathrm{xx}$, que desenvolve outros modos de fazer teatro em consideração à ativação do espectador.

Além das pesquisas desenvolvidas no campo da arte, estudos advindos da filosofia, da antropologia, da biologia e das ciências cognitivas, permitem a ampliação das noções de recepção da arte por meio de pesquisas sobre o corpo e seus modos de percepção. Alguns exemplos podem ser citados aqui, como: o desenvolvimento da noção de embodiment (mente incorporada) que se baseia na ideia de que não há qualquer indício de uma mente fora do corpo (físico), e que percebe o corpo como processo dinâmico de auto-organização/ regulação ${ }^{2}$; o mapeamento de níveis de reação dos espectadores, por meio da investigação de suas ativações neurológicas e atividades psicológicas diante do fenômeno teatral, desenvolvido pelo pesquisador francês Yannick Bressan (2014) e sua equipe multidisciplinar, afirmando que seria possível manipular

2 O entendimento de corpo que é proposto neste escrito parte da consideração de que corpo e mente não são duas coisas separadas, mas uma só e mesma coisa que se manifesta de modos distintos (Spinoza, 2009 [1677]), permitindo-nos entender que o sujeito é o corpo, e não possui um corpo comandado por uma força exterior a ele (Nunes, 2009), e que se trata de um "ente-em-vida" em constante estado de instabilidade e auto-organização, um organismo que agencia a experiência vivida (Bernard, 2001). 
a percepção do espectador ${ }^{3}$; e um último exemplo, a descoberta dos neurônios espelho pelos neurocientistas italianos Giacomo Rizzolate, Vittorio Gallese e Leonardo Fogassi, que identificam a possibilidade de, ao sermos expostas/ os a determinadas ações, as regiões do cérebro vinculadas ao movimento são ativadas, fazendo-nos simular a ação observada como se a realizássemos (Blakeslee, 2006) ${ }^{4}$.

Tais pesquisas contribuem com o desenvolvimento de técnicas no contexto das artes presenciais contemporâneas permitindo que a produção prévia, a composição dos trabalhos a serem levados à relação com o público, tenha elementos referentes aos aspectos biológicos-culturais do corpo a serem articulados na proposição artística. Porém, por se tratar de relações entre subjetividades, de construções e conexões singulares e em movimento constante, não se pode garantir a assertividade acerca da recepção. Se Spinoza (2009 [1677]) afirma que os afetos que incorrem nos encontros não são passíveis de previsão, ao tomarmos essa afirmação como princípio na ação artística, a ideia de que se pode prever, controlar a recepção do público e dominar o espaço perde força.

Apesar da possibilidade de se desenvolver uma proposição baseando-se em estudos estatísticos de comportamento e/ou nos próprios afetos diante de determinados encontros, acreditando na possibilidade de afetar o outro por adesão, empatia, ou pela ação dos neurônios espelho, por exemplo, ainda assim, não se tem a garantias de que a experiência venha a ser igual para todas

3 Em busca da descoberta do que conferiria eficácia à representação teatral, Bressan e uma equipe multidisciplinar (ligada às neurociências, estética, estudos teatrais e psicologia cognitiva) descobrem o 'Princípio da adesão emergentista' (PAEm), compreendido como um fenômeno psicocognitivo que leva um sujeito a "construir uma realidade para a qual ele vai dar, mais ou menos conscientemente, uma força de existência a tal ponto que essa realidade emergente se tornará a realidade do sujeito aderente" (Bressan, 2014, p. 252). Em outra publicação, Bressan e sua equipe interrogam o que as mudanças fisiológicas e cerebrais dizem sobre e adesão a uma representação, identificando qual padrão de resposta do cérebro diante da representação e também qual a variabilidade dinâmica da frequência cardíaca do sujeito. As descobertas levam à hipótese de que mudanças sutis no estado de consciência dos sujeitos ocorrem diante da exposição e adesão ao que assistem, explicando que o fenômeno da adesão à ficção dramática acontece diante do modo como decorrem as articulações prévias da encenação que pretendem o engajamento do espectador em seu universo ficcional (Metz-Lutz, Bressan, Heider, Otzenberger, 2010).

4 Ao fazerem uma experiência sobre a atividade neural de um macaco na Universidade de Parma em 1996, os pesquisadores Giacomo Rizzolate, Vittorio Gallese e Leonardo Fogassi, identificaram que os neurônios pré-motores do animal eram ativados diante da sua exposição à ação de um dos cientistas, que era a de pegar um alimento, descobrindo com isso os neurônios espelho (Blakeslee, 2006). 
as pessoas envolvidas. Por esse motivo, a defesa da centralidade da figura do artista, com uma presença ensimesmada, cheia de aura, já não teria fundamento em um contexto de conexões emergentes, de relações que necessitam de uma constante atualização diante da percepção do nível de engajamento dos corpos na ação proposta.

Descartar uma presença cheia de aura para, ao invés disso, considerar as presenças do ambiente na tentativa de descobrir potência de afeto nas emergências desse encontro no aqui-agora, aparece como um posicionamento mais condizente com uma recepção ativa. Um corpo poroso, capaz de escutar/ perceber o que ocorre no ambiente, se mostra como possibilidade na configuração de uma presença-convite (Duenha, 2014), essa que pode produzir engajamentos, mas que também é engajada, que propõe, mas que também identifica a sutileza das re(l)ações, construindo co-moções. Uma ideia de presença partilhada estaria na responsividade, no ato de tomar parte, ao modo de Rancière (2005, p. 15) "a maneira comum que se presta a participação e como uns e outros tomam parte nessa partilha”. A partilha de algo que se estabeleça no encontro, como potência de um acontecimento delineado na emergência das relações entre as presenças no aqui-agora, e não necessariamente dependente de uma presença previamente estruturada, que talvez possa ser foco de admiração, mantendo-se, porém, impermeável.

Se a arte se destina à criação de fissuras perceptivas, um modo de fazer "em relação" deveria considerar o para/com quem se faz, ou seja, os corpos presentes no ambiente, corpos esses que não se conformam, pois como nos traz a psicanalista brasileira Suely Rolnik (1996), somos, como indivíduos, habitados permanentemente por fluxos de todo o planeta. Para ela, a figura do/da artista como aquele/aquela que propõe é também um corpo vibrátil em favor de novas composições, que oferece condições para o público receptor, mas que também se permite a desconstrução de formas (Rolnik, 1996).

Diante de tais afirmações, a manutenção de uma divisão entre aquele que é dotado de talento, de luz, de presença cênica e aquela audiência passiva, como Rancière (2010) problematiza, parece reforçar as relações de poder, de hierarquias. Às artes da presença e seus modos de fazer, não parece mais admissível uma manutenção do lugar de certezas, de domínio e segurança acerca dos modos de recepção das pessoas participantes. Por outro lado, esse modo de fazer em relação (que inclui noções de treinamento, desenvolvimento de técnicas e formas de se colocar com a/o outra/o) também não implica 
em displicência, no esquecimento de um rigor no fazer prévio, implica em refinamento da atenção, em afinação perceptiva, para tornar o corpo e as proposições por ele desenvolvidas uma estrutura porosa, aberta aos afetos do encontro e capaz de atualizar-se em ato.

\section{Uma experiência do Coletivo Mapas e Hipertextos}

Que alterações nos modos de fazer arte contemplariam uma noção de presença compartilhada, de modo que se descubra possibilidades relacionais metaestáveis nessas ondas imprevisíveis que emergem entre proposição e recepção? Algumas experimentações no processo criativo do coletivo 'Mapas e Hipertextos', se direcionam a tal investimento, das quais se extraem tanto efeitos mais assertivos e previsíveis, quanto inesperados, alimentando uma produção que se dá em constante movimento.

O coletivo 'Mapas e Hipertextos' é um espaço para pesquisa e desdobramento de conceitos em artes presenciais a partir de articulações de questões que tocam a dimensão do político. Seu nome diz também de seu modo de operação. Parte sempre de mapeamentos de espaços virtuais e físicos na intenção de desdobrar temáticas relacionadas à vida em sociedade e modos de inserção compositiva nos espaços. Os possíveis vetores de criação diante dessa prática somam-se a referências de imagens, discussões de conceitos e desenvolvimento de fragmentos compositivos que são combinados e recombinados na execução de ações performáticas realizadas presencialmente e/ou veiculadas em distintos suportes, como vídeo e fotografia. Como coletivo, se mantém em busca de um modo de funcionamento menos hierárquico seguindo um sistema de divisão de tarefas e lideranças temporárias, mantendo um revezamento de posições. Cada nova decisão é discutida no grupo e leva em conta todos os pontos de vista até que se chegue a uma opção de consistência a partir de todas as considerações.

Por que parece importante a exposição do modo de funcionamento do coletivo 'Mapas e Hipertextos'? Porque, na intenção de fazer com que conceitos direcionem práticas e práticas permitam a emergência de conceitos e modos de fazer nas artes da presença há, primeiramente, o investimento na alteração das relações internas, experimentando possibilidades de se criar procedimentos em arte que possam contaminar também nossas relações em 
sociedade e vice-versa. Assim, uma pequena parte desse processo é aqui exposta, na intenção partilhar investidas, colocar em questão algumas possibilidades relativas à produção e recepção em artes presenciais e de trazer uma perspectiva mais encarnada da discussão evocada aqui. Como modo de assumir as implicações, como corpo que compôs esse processo, manterei a narração com o emprego de pronomes em primeira pessoa no singular e no plural.

\section{0 processo de criação}

Partimos de nossos afetos. Na tentativa de mapear uma questão a ser desdobrada no processo coletivo no início do ano de 2014, chegamos à seguinte pergunta: o que nos provocava o sentimento de indignação? Passamos, então, a observar situações cotidianas que nos ofereciam a ideia de violação, que provocavam certa paralisia. Começamos a experimentar algumas possibilidades compositivas. Observamos inicialmente nossas sensações diante de acontecimentos desse teor, mapeamos estados do corpo e desenvolvemos alguns textos descritivos desses estados.

Figura 1. Registro do processo de experimentação compositiva acerca do tema 'indignação' desenvolvido no dia 25/05/2014
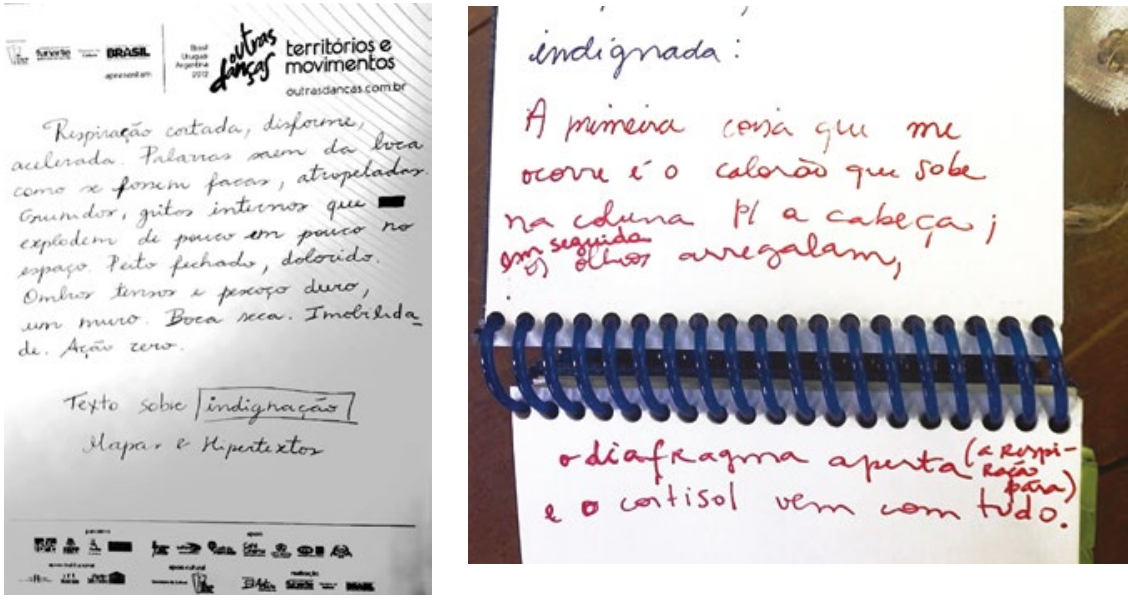

Fonte: Acervo do grupo 
Inventamos uma estrutura na qual uma pessoa narrava sequencialmente esses estados, e as outras pessoas, dispostas em linha reta, transformavam as palavras em movimentos. Surgiram muitos movimentos e imagens e muitas delas tinham um caráter risível. Um procedimento investigativo do grupo é a tentativa de permanência no exercício até seu esgotamento/transformação. A permanência nesse procedimento nos fazia passar pelo óbvio, pelo clichê, pelo ilustrativo, mas também nos fazia intensificar as ações até a emergência de outras imagens inusitadas contaminadas por uma diferenciação no próprio estado emocional vivenciado no momento. Em mim, riso e choro se misturavam na tentativa de desdobrar a narração com a articulação/manifestação do que acontecia ao corpo naquele aqui-agora. Via a indignação experimentada sendo ridicularizada. $\mathrm{O}$ modo como as outras integrantes do coletivo se empenhavam para evidenciar, com pequenas ações, a narração de minhas sensações de violação provocava-me sobremaneira. Essas percepções eram partilhadas pelas demais integrantes do coletivo. Tínhamos ali uma pista para produzir certo vínculo entre quem expõe suas reações de indignação e quem as desdobra.

Desenvolvemos uma ação modular que iniciava com fragmentos compositivos elaborados a partir do recorte de cada uma de suas indignações e incluímos, ao final, o procedimento de narração das sensações diante de situações de violação e manifestação em movimento do que era narrado. Uma de nós narrava as sensações do corpo enquanto todas as outras corporificavam essas sensações, vestidas até a cintura com sacos de lixo. Imagens de vídeo de outras ações desenvolvidas previamente pelo coletivo eram também projetadas sobre nossos corpos nesse momento.

Para concluir essa ação, um último fragmento compositivo foi desenvolvido: decidimos ampliar o conjunto de descrições escolhendo incluir as sensações do público por meio de uma coleta/entrevista anterior à realização da ação. Algumas pessoas presentes eram questionadas sobre a percepção de suas reações corporais diante do sentimento de indignação. Algumas integrantes do grupo perguntavam: como seu corpo reage diante de uma situação que te deixa indignada/indignado, quais são as sensações e como se manifestam? As respostas criaram uma lista extensa e inusitada de descrições às quais não tínhamos acesso prévio, pois, após coletadas separadamente, elas eram reunidas de modo aleatório e lançadas durante a ação com o público. Essa proposta fez percebermos que a narração também poderia partir do público 
ao disponibilizarmos um microfone e convidá-los a ocupar nosso lugar em algum momento da ação. Tal situação nos desafiava a improvisar também a partir das palavras das pessoas participantes e da imprevisibilidade de suas ações ao aceitar trocar de posição conosco.

Essa investida em incluir na composição a proposição-convite ao público aparecia como a oportunidade de criarmos algo em comum, evidenciando uma participação mais ativa do público, acionando uma noção de responsividade. Eu estava particularmente interessada em observar o andamento da proposta com um engajamento mais manifesto de quem se mantinha no lugar de espectador/a e por isso me ocupava em mapear com o olhar como o público reagia, partindo da percepção dos modos de adesão e de mobilidade dos corpos na experiência proposta. A ideia era a de que partilhássemos tanto $o$ ato de impulsionar quanto o de experimentar os movimentos que acontecem no corpo como reações à indignação. Em dado momento, convidávamos o público a ocupar nossos lugares de narração e corporificação das sensações narradas e, além disso, a decidirem até quando o jogo seria mantido, uma vez que resolvemos que o final da performance deveria ser determinado pelas pessoas que ocupassem nossos lugares.

\section{Descrição da estrutura de ações/proposições que antecedem um final-imprevisto}

Os fragmentos compositivos desenvolvidos a partir de questões pessoais a respeito do tema 'indignação' surgiram, após alguns dias de observação de acontecimentos no cotidiano que nos causavam sensações de violação, paralisia, dentre outras. Cada performer ficou responsável por apresentar sua pesquisa às demais integrantes do grupo. As propostas giravam em torno de questões como sujeição a determinadas formas de poder, silenciamento e anulação da capacidade de ação, e desejo de violência. Um dos fragmentos tratava da ideia de fracasso perante algumas exigências da vida em sociedade: uma das artistas, Cecília Lauritzen, expunha ao público seus dilemas, suas falhas como atriz durante o processo criativo fazendo-o em um discurso inflamado, acessando um estado de descontrole. Outro, com Paloma Bianchi, abordava a questão da culpabilidade da mulher em situações de assédio e/ou estupro: ela passava um áudio (em aparelhos de MP4 player) com a gravação de diversos 
comentários machistas de homens e mulheres coletados em redes sociais acerca do comportamento feminino, sobre o tipo de roupa que as mulheres usam, e que, teoricamente, provocaria o estuprador. Enquanto isso, a artista vestia uma grande quantidade de roupas sobrepostas até perder a mobilidade. Outro fragmento, com ações realizadas por mim, tratava do constrangimento e da paralisia diante de uma situação de humilhação: eu relatava o dilema da tentativa de resolução de uma cobrança indevida de cartão crédito, a qual o banco se negava a assumir. Fazia isso me equilibrando em superfícies instáveis de madeira com outras integrantes do grupo tentando me calar ao por objetos e roupas em minha boca. Enquanto isso, uma imagem de santo com o nome de 'Santo Ander' passava pelo público em uma cesta de recolha de dinheiro. A última ação modular que compunha a performance era a de narração e corporificação das sensações vinculadas à indignação, como relatado anteriormente. O trabalho ganhou o título ‘Sobre (im) posição nos Anais Vol.7', e foi levado ao público no dia 25 de junho de 2014 no pátio interno do Centro de Artes da Universidade do Estado de Santa Catarina (UDESC), como parte da programação da 'Semana Performática da UdESC's.

Apesar de termos planejado uma sequência de ações compondo a performance que duraria cerca de 30 minutos, o que ocorreu na relação com o público nos surpreendeu grandemente. Em vários momentos nós as/os convidávamos a um engajamento sensorial nas ações, e em outros as/os convidávamos também a interferir naquilo que fazíamos. A relação espacial entre nós e o público era próxima, em formato semicircular, olhávamos diretamente para as pessoas, as convidávamos a sugerir por onde poderíamos passar durante a performance. Além disso, elas tinham a tarefa de passar umas para as outras os aparelhos de MP4 player com os áudios, a cesta que trazia o 'Santo Ander' e ainda podiam escolher entre colocar ou não colocar dinheiro para o santo. Ao final, no momento de trazer as descrições do público acerca de suas sensações na indignação... Surpresa!

Nada do que havíamos previsto para esse momento aconteceu, a adesão foi muito pequena e o tempo da ação se dilatou. Em vez de ser marcado pela desistência do público participante, o final foi se prolongando na

5 Esse evento foi uma iniciativa da $\operatorname{Prof}^{a}$. Dra . Daiane Dordete, responsável pelo 'Laboratório Permanente de Performance' do Centro de Artes da Universidade do Estado de Santa Catarina, na cidade de Florianópolis, Santa Catarina, Brasil. 
permanência e no aparente incomodo daqueles que continuavam a realizar as ações de narração e corporificação das sensações. Tivemos aí uma oportunidade de entender o quanto não podemos prever a recepção daqueles que dividem a experiência presencial conosco. Percebemos também, com isso, a necessidade de nos fazermos presença-convite sem dependermos de uma implicação do público muito manifesta fisicamente. O público aparentemente se envolveu nas ações anteriores, movendo-se, agindo como interlocutores ativos, mas nessa ação que em nosso olhar continha mais potência, o efeito foi bem diferente do esperado. O que nos tinha arrancado gargalhadas, e nos provocado diferentes sensações, se quer conquistava sorrisos. Havia apenas olhares de estranhamento, um aparente prazer e alguns relatos posteriores de empatia diante das situações apresentadas. A eficácia já não parecia garantida. Ao ser realizada em outro contexto, diferente daquele que a sala de ensaio nos oferecia, a ação ganhava outros efeitos, que não os previstos. Alguns espectadores participantes (amigos nossos) aceitaram ocupar nossos lugares de narração e de transformação da sensação em movimento diante de nosso convite. Não por um explícito envolvimento no que fazíamos, mas por uma aparente compaixão. Nós deduzimos a resposta do público e por mais que nos sentíssemos abertas e preparadas para suas reações, nos surpreendemos.

O que nos traria a segurança acerca do nível de engajamento do público ao ponto de esperarmos sua interferência nas ações? A participação acontecia, aparentemente, como envolvimento, como direcionamento da atenção, mas não parecia suficiente para impulsioná-los a performar conosco. Nós tratávamos de uma questão comum, do sentimento de indignação, questionando como percebiam-se quando indignados com algo. Os relatos de algumas pessoas do público estavam ali contemplados, porém, não poderíamos esperar muito mais do que o nível de envolvimento que aconteceu nesse encontro.

Depois de vivenciarmos essa experiência com o público na 'Semana Performática', nós começamos a investir em outras formas de acesso à questão da violação que nos ficou mais evidente. Uma das ações que emergiram foi derivada desse procedimento anterior que contemplava as descrições das sensações do público. Passamos a coletar as percepções das reações de indignação das pessoas presentes antes de cada momento de realização da performance. Vários procedimentos se alteraram na continuidade do processo, inclusive a ação desenvolvida a partir disso: o modo de abordagem do público passou 
a ser muito mais informal e afetuoso. Conversávamos em pequenos grupos, permanecíamos um tempo juntos, como em uma recepção de festa, e pedíamos seus relatos acerca das sensações de indignação ao final da conversa. Após esse momento de recepção, Cecília Lauritzen reunia todos os relatos, os organizava e tentava memorizá-los. Em dado momento, ela passava a narrar e corporalizar as frases coletadas convertendo-as para pronomes de primeira pessoa do singular, como se tudo acontecesse com ela. Ao final do trabalho, algumas pessoas vinham nos dizer sobre a expectativa de que ela falasse sua reação, ou da curiosidade sobre quem teria dito tal frase. O efeito era outro, nesse caso, o público mostrava muito mais adesão ao que acontecia. Havia uma alteração da postura corporal de algumas pessoas, que inclinavam-se na direção da performer, outras riam de muitas frases e pareciam contempladas com o que acontecia ali. A implicação dos corpos na ação se tornava mais evidente e sua participação mais manifesta, porém, sem imposição e exposição demasiada das pessoas presentes.

\section{E-feitos}

Se nas duas realizações da ação modular desenvolvida pelo coletivo 'Mapas e Hipertextos' a estrutura de frases e captação de relatos era a mesma, o que teria provocado o maior engajamento do público na segunda ocasião? A meu ver, pequenas alterações de atitude de nossa parte provocou uma diferença estrutural nas relações: assumimos o que era de nossa responsabilidade como artistas propositores, nos desarmamos do excesso de expectativas sobre a manifestação do público e tentamos substituir uma presença mais impositiva, que demandava uma atividade corporal do público a partir de nossas propostas, por uma presença que considerava as alterações de todos os corpos envolvidos na relação, cada qual com sua medida de manifestação.

Outro conjunto de fatores também teve ressonância nessa segunda ocasião. A ação de ir ao encontro das pessoas tornando o ambiente um espaço de encontro, e não um local de apresentação, era uma tentativa de desmanchar uma antiga fronteira criada entre espectador e artista, entre aquele que propõe e aquela que assiste. Quando saíamos para conversar com o público, nós nos expúnhamos como pessoas desarmadas de "presença cênica", buscando uma aproximação, uma relação mais íntima e individualizada. Quando a pessoa via 
seu relato compondo nossa dramaturgia, ela já estava, de certo modo, ciente de que era parte daquilo, e que o que fazíamos era apenas dividir aquilo que nos era comum: as sensações vinculadas à indignação. A performer, Cecília Lauritzen, também tinha uma postura de direcionar o olhar para cada pessoa, como se dividisse um segredo, em uma relação bastante íntima. Vale ressaltar, que o número de pessoas a cada ação não era grande, entre cinquenta e setenta pessoas, o que facilitava um contato mais direto. Já havíamos optado por não utilizar a relação espacial de palco italiano, que tem o público à frente e abaixo do artista, mas manter uma relação próxima e de igualdade de níveis, mantendo também todo o espaço iluminado, sem utilização de uma luz diferenciada para quem realizava as performances.

Com algumas alterações na abordagem do público, e no modo de apresentação da proposta, outros caminhos se abriam para nós em direção a um fazer que já não parece caber no lugar do poder e do saber. Não se tratava de acertar o que iria acontecer em relação à recepção, mas o fato de termos assumido a imprevisibilidade e deixado a relação acontecer de modo mais sutil, menos expositiva e menos exigente no sentido de participação manifesta, outras recepções de diferentes níveis de engajamento passaram a ser possíveis para nós. Uma presença partilhada apareceu como efeito de um olhar para si, de uma transformação do fazer na relação, como efeito de uma porosidade, e não como efeito de uma criação genial capaz de deixar todas as pessoas boquiabertas diante do espetáculo. Foi possível perceber que espetáculo não era uma palavra que definiria nosso fazer.

Ao nos posicionarmos como artistas de modo mais aberto à relação já na recepção das pessoas que vinham ao nosso encontro, entendendo-as como aquelas que são convidadas a um estar junto, as convidávamos também a compor o ambiente e, aparentemente as deixávamos mais suscetíveis à adesão às proposições e à percepção dos afetos do encontro. Isso se desenhava por um modo menos armado de presença de ambos os lados. A propósito, não havia mais lados, uma linha divisória entre público e artista, mas uma mistura de corpos porosos que fazia único cada encontro. Tal situação aparecia como confirmação da arte da presença como aquilo que não se repete, uma vez que cada novo encontro é determinado pelas presenças que ali o fazem. 


\section{Considerações}

A experiência do coletivo 'Mapas e Hipertextos' não se revela como exemplo de assertividade, de resposta às questões sobre presença levantadas inicialmente nesse texto, mas como um possível desdobramento das perguntas, ora caindo em armadilhas de previsão acerca dos afetos do encontro, ora distanciando o púbico com os efeitos de nossa presença cênica dilatada, ora produzindo aproximações, manifestações, mas à medida do teor do encontro, na composição entre as presenças do ambiente. Outras práticas foram desenvolvidas posteriormente nesse coletivo considerando modos menos impositivos de presença. As noções de presença-convite (Duenha, 2014) e de responsividade seguiram em articulação nas criações posteriores, mas sempre em questionamento e refeitura. A partir da percepção de que o ambiente é composto pelos corpos, mas também os compõem, permite-nos perguntar sobre nossa forma de ser/estar presentes como arte em uma relação sempre a retomar.

A possibilidade de mobilizar, na prática artística presencial, questões tão caras a esse fazer, como as que envolvem as noções de presença, aparece como desafio a artistas que se disponibilizam, uma vez que se trata de um convite à habitação de um terreno incerto que implode perspectivas baseadas em noções de certo e errado, sucesso e fracasso. Desafiar saberes prévios da arte em relações menos dicotômicas e hierarquizadas também se revela como uma forma de evocar diferentes modos de participação e compartilhamento, e isso ocorre em um diálogo estreito com as dinâmicas inerentes ao convívio em sociedade.

A emancipação evocada por Rancière (2010) tem vazão na percepção das formas de posicionamento do indivíduo perante o coletivo, no ato de tomar parte naquilo que se desvenda como comum situado, evidenciando o modo como isso acontece na esfera da política de relações. As co-moções que os atos de compartilhar demandam não permitem que os envolvidos na experiência se mantenham da mesma forma, afinal, como nos traz Spinoza (2009 [1677]), somos afetadas/os pelos corpos independentemente de nossa vontade.

Os elementos de sondagem que emergem de pesquisas voltadas à recepção, a exemplo do 'Princípio de Adesão Emergentista' de Bressan (2014) e sua equipe, as pesquisas voltadas à preparação do/da performer como se vê em Barba (1995), ou mesmo a abordagem do corpo fenomênico e da presença, como fazem Fischer-Lichte (2011) e Jaeger (2006) respectivamente, 
são extremamente relevantes no que concerne à articulação compositiva que se antecede à posta em relação nas artes da presença, além de oferecerem, cada qual a seu modo, estratégias de convite e abertura necessárias ao jogo em tempo real.

Mapear os meios pelos quais as relações podem se dar no encontro na arte é mais um modo de ampliar a percepção para as afecções que marcam o corpo nesse acontecimento irrepetível que ocorre na arte ao vivo. Porém, fazer arte sem levar em consideração medidas de sujeição e emancipação que algumas abordagens incitam, sem considerar uma demanda de flexibilidade nas negociações entre as presenças daqueles que partilham a experiência no aqui-agora, nos expõe ao risco de sustentar operações que reiteram sistemas enrijecidos e ameaçadores do convívio democrático.

\section{Referências}

Barba, E. (1995). A arte secreta do ator: Dicionário de Antropologia Teatral (P. Furtado de Mendonça, Trad.). São Paulo: Hucitec Unicamp.

Bernard, M. (2001). La corporeité comme 'anticorps'. Em De la création chorégraphique (pp. 17-25). Paris: Centre National de la danse.

Blakeslee, S. (2006). Os neurônios que podem ler mentes: Células cerebrais chamadas de espelho são capazes de analisar cenas e interpretar as intenções dos outros. Jornal da Ciência, 30. Recuperado de http://www.jornaldaciencia.org. br/Detalhe.jsp?id=34918

Bressan, Y. (2014). O Teatro e o Princípio de Adesão Emergentista, Revista Brasileira de Estudos da Presença, 4(2), 249-262. DoI: https://doi.org/10.1590/2237266043411

Metz-Lutz, M-N., Bressan, Y., Heider, N. e Otzenberger, H. (2010). What physiological changes and cerebral traces tell us about adhesion to fiction during theater-watching? Front. Hum. Neurosci, 4, 59. DoI: 10.3389/fnhum.2010.00059

Duenha, M. L. (2014) Presença e (em) relação: A potência de afeto no entre corpos. Programa de Pós-Graduação em Teatro - Universidade do Estado de Santa Catarina - Florianópolis, Dissertação (Mestrado em Teatro) Recuperado de http://tede.udesc.br/handle/tede/1183

Fischer-Lichte, E. (2011). Estética de lo performativo (D. González Martín e David Martínez Peruch, Trads.). Madrid: Abada. 
Jaeger, S. (2006). Embodiment and Presence. The Ontology of Presence Reconsidered. Em D. Krasner, e D. Saltz, Orgs.), Staging Philosophy. Intersections of Theater, Performance and Philosophy (pp. 122-141). Michigan: The University of Michigan Press.

Nunes, S. M. (2009). As metáforas do corpo em cena. Florianópolis: AnnaBlume/ UDESC.

Spinoza, B. (2009 [1677]). Ética (Parte II: Da natureza e da origem da alma, e Parte III: Da origem e da natureza das afecções; T. Tadeu, Trad.). Belo Horizonte: Autêntica Editora.

Rancière,J.(2010).Oespectadoremancipado.Urdimento-RevistadeEstudosem Artes Cênicas, 1(15), 107-122. Dor: https://doi.org/10.5965/1414573102152010107

Rancière, J. (2005). Rancière, Jacques. A partilha do sensível: Estética e política (M. Costa Netto, Trad.). São Paulo: 34.

Rolnik, S. (1996). Lygia Clark e o híbrido arte/clínica. Percurso - Revista de Psicanálise, VIII(16), 43-48. Recuperado de http://caosmose.net/suelyrolnik/ pdf/Artecli.pdf 